\title{
Evidencia neuroanatómica del transporte del virus de la rabia por la vía propioespinal de la médula espinal de ratones
}

\author{
Gerardo Santamaría1, Jeison Monroy-Gómez ${ }^{1,2}$, Orlando Torres-Fernández \\ 1 Grupo de Morfología Celular, Instituto Nacional de Salud, Bogotá, D.C., Colombia \\ 2 Departamento de Ciencias Básicas, Institución Universitaria Escuela Colombiana de Rehabilitación, Bogotá, D.C., \\ Colombia
}

Introducción. Es escasa la información sobre los detalles neuroanatómicos del transporte del virus de la rabia en su ascenso por la médula espinal.

Objetivos. Identificar la ruta neuroanatómica de diseminación del virus de la rabia en cada uno de los niveles de la médula espinal de ratón, después de ser inoculado por vía intramuscular.

Materiales y métodos. Se inocularon ratones en los músculos isquiotibiales, con virus de la rabia. A partir de las 24 horas después de la inoculación, cada ocho horas se sacrificaron cinco animales por perfusión con paraformaldehído, se les extrajo la médula espinal y se hicieron cortes transversales en los niveles lumbosacro, torácico y cervical. Estos se procesaron mediante inmunohistoquímica para detectar antígenos virales.

Resultados. Los primeros antígenos de la rabia se observaron como partículas agregadas, en la médula espinal lumbar, a las 24 horas después de la inoculación, dentro del asta ventral ipsilateral a la extremidad inoculada. A las 32 horas después de la inoculación, se hicieron visibles las primeras motoneuronas inmunorreactivas al virus. A las 40 horas después de la inoculación, se revelaron las primeras neuronas inmunorreactivas en la médula torácica, localizadas en la lámina 8 y, a las 48 horas después de la inoculación en la médula cervical, también en la lámina 8. A las 56 horas después de la inoculación, el virus se había diseminado por toda la médula espinal pero los animales aún no revelaban signos de la enfermedad.

Conclusión. En el modelo de ratón aquí utilizado, el virus de la rabia ingresó a la médula espinal por las motoneuronas y, probablemente, utilizó la vía propioespinal descendente para su transporte axonal retrógrado hasta el encéfalo.

Palabras clave: virus de la rabia; médula espinal; transporte axonal; inmunohistoquímica; neuronas motoras; ratón.

doi: https://doi.org/10.7705/biomedica.v38i0.3711

\section{Neuroanatomical evidence of the transport of the rabies virus through the propriospinal tract in the spinal cord of mice}

Introduction: Information about the neuroanatomical details of the ascendant transport of the rabies virus through the spinal cord is scarce.

Objective: To identify the neuroanatomical route of dissemination of the rabies virus at each of the levels of the spinal cord of mice after being inoculated intramuscularly.

Materials and methods: Mice were inoculated with the rabies virus in the hamstrings. After 24 hours post-inoculation, every eight hours, five animals were sacrificed by perfusion with paraformaldehyde. Then, the spinal cord was removed, and transverse cuts were made at the lumbosacral, thoracic, and cervical levels. These were processed by immunohistochemistry for the detection of viral antigens.

Results: The first antigens of rabies were observed as aggregated particles in the lumbar spinal cord at 24 hours post-inoculation, within the ventral horn in the same side of the inoculated limb. At 32 hours post inoculation the first motoneurons immunoreactive to the virus became visible. At 40 hours postinoculation the first immunoreactive neurons were revealed in the thoracic level, located on lamina 8 and at 48 hours post-inoculation in the cervical cord, also on lamina 8 . At 56 hours post-inoculation the virus had spread throughout the spinal cord, but the animals still did not show signs of the disease.

Conclusion: In the mouse model we used, the rabies virus entered the spinal cord through the motoneurons and probably used the descending propriospinal pathway for its retrograde axonal transport to the encephalus.

Key words: Rabies virus; spinal cord; axonal transport; immunohistochemistry; motor neurons; mice. doi: https://doi.org/10.7705/biomedica.v38i0.3711

\section{Contribución de los autores:}

Gerardo Santamaría y Jeison Monroy-Gómez: desarrollo de los experimentos

Orlando Torres-Fernández: idea y dirección general del trabajo

Todos los autores participaron en la planeación y diseño del trabajo, el análisis de resultados y la escritura del manuscrito. 
El virus de la rabia es un agente patógeno neurotrópico, selectivo del sistema nervioso. Se podría ser más específico al afirmar que es un virus 'neuronotrópico', porque infecta a las neuronas y es raro encontrarlo en otro tipo de célula.

Desde la época de Pasteur y durante las primeras décadas del siglo $X X$, se pensaba que el virus era transportado por los nervios periféricos hasta el sistema nervioso central, aunque algunos investigadores no descartaban la posibilidad de su diseminación por vía sanguínea. Para la década de los años 70 , después de varios trabajos experimentales y estudios con técnicas de inmunofluorescencia y microscopía electrónica, hubo consenso en aceptar la vía nerviosa como la ruta exclusiva de diseminación del virus de la rabia, aunque sin conocer los detalles de los mecanismos de transporte $(1,2)$. Casi simultáneamente, se descubrió el transporte axonal retrógrado de proteínas y otras moléculas (3). Con base en estos antecedentes, en 1979 Tsiang llevó a cabo la primera demostración experimental del transporte axonal retrógrado del virus de la rabia (4).

Posteriormente, se comprobó que el virus, inoculado por vía intramuscular o a través de las almohadillas plantares de las extremidades posteriores de ratones, era detectado inicialmente en las neuronas motoras del asta ventral de la médula espinal, antes que en los ganglios espinales (5). La hipótesis del transporte axonal retrógrado del virus de la rabia se afianzó después de realizar experimentos de inoculación estereotáxica del virus en núcleos neuronales específicos del encéfalo de ratas, y su posterior detección con inmunohistoquímica en el sitio de origen de las neuronas aferentes al área de inoculación. Además, se postuló al virus de la rabia como una herramienta útil para el trazado de las vías neuroanatómicas (6).

Actualmente, los investigadores especializados en rabia, con base en las evidencias conocidas, prefieren aceptar la hipótesis del ingreso y la diseminación del virus por la vía motora y mediante el transporte axonal retrógrado $(2,7,8)$. No obstante, algunos autores han reportado vulnerabilidad de las neuronas sensoriales ante la infección y transporte

Correspondencia:

Orlando Torres-Fernández, Grupo de Morfología Celular, Instituto Nacional de Salud, Avenida Calle 26 № 51-20, Bogotá, D.C., Colombia

Teléfono: (571) 220 7700, extensión 1262

otorresf@ins.gov.co

Recibido: 05/12/16; aceptado: 12/09/17 axonal anterógrado del virus en condiciones in vitro $(9,10)$, así como su posible ingreso al sistema nervioso central por la vía sensorial $(11,12)$. Además, existe un virus recombinante de la rabia, obtenido por deleción de la proteína G, que puede infectar neuronas sensoriales y ser transportado en dirección anterógrada $(13,14)$.

En el presente estudio, se presentan los resultados del seguimiento a la trayectoria de los antígenos virales dentro de la médula espinal de ratón, después de la inoculación intramuscular del virus. Se describe su ascenso y localización en las láminas de Rexed (15), en los segmentos lumbar, torácico y cervical de la médula espinal.

\section{Materiales y métodos}

\section{Inoculación y manejo de animales de laboratorio}

En este trabajo se utilizaron hembras de ratones ICR (Institute of Cancer Research) de 28 días de edad, mantenidas en una sala de alta seguridad biológica del bioterio del Instituto Nacional de Salud, en condiciones ambientales y nutricionales óptimas, de acuerdo con las normas éticas y legales exigidas para la investigación con animales de laboratorio.

Para la conformación de los grupos de experimentación, los animales se seleccionaron al azar. Se utilizó virus fijo CVS (Challenge Virus Standard) de la rabia, suministrado en alícuotas por el Laboratorio de Virología del Instituto Nacional de Salud.

Inicialmente, se inocularon diez ratones de 21 días, por vía intracerebral, para aumentar la cantidad de virus disponible para los experimentos. A partir de macerados de estos cerebros infectados, se obtuvieron alícuotas de diluciones seriadas para llevar a cabo la titulación, según el método modificado de Reed y Muench (16). Cada alícuota se diluyó en una solución preparada con agua destilada, suero equino normal al $2 \%$ y antibióticos (200 Ul/ ml de penicilina y $4 \mathrm{mg} / \mathrm{ml}$ de estreptomicina).

Los ratones del experimento se inocularon por vía intramuscular, cada uno con $0,03 \mathrm{ml}$ de una solución viral diluida $10^{-1}$ equivalente a $10^{6} \mathrm{LD}_{50}$. La inoculación se llevó a cabo en los músculos isquiotibiales del miembro pélvico izquierdo. Cada ocho horas, a partir de las 24 horas después de la inoculación y hasta las 56 horas después de la inoculación, se sacrificaron cinco animales inoculados con el virus y dos controles, como se describe a continuación. Cinco animales más fueron sacrificados en la fase avanzada de la enfermedad 
(120 horas después de la inoculación) y, también, dos controles. En total, se utilizaron 42 animales en el experimento.

Los ratones fueron anestesiados con una inyección intraperitoneal de $1 \mathrm{ml}$ de hidrato de cloral al $30 \%$. A continuación, se sometieron a perfusión intracardiaca, inicialmente con $50 \mathrm{ml}$ de solución amortiguadora de fosfatos (PBS) con $\mathrm{pH} 7,2$, y después, con $100 \mathrm{ml}$ de una solución de fijación compuesta por paraformaldehído al $4 \%$ preparada en PBS. Inmediatamente, se extrajeron las médulas espinales y se transfirieron a frascos con solución de fijación fresca. La extracción de la médula espinal se llevó a cabo mediante disección sin descalcificación previa de la columna vertebral.

El protocolo de manejo de animales fue aprobado por el Comité de Ética del Instituto Nacional de Salud (Acta 4-2014 del 29 de mayo de 2014).

\section{Inmunohistoquímica}

Los segmentos de la médula espinal se incluyeron en agar al $3 \%$ y se montaron en un vibrátomo, para obtener cortes transversales de $50 \mu \mathrm{m}$ de espesor, en los niveles medulares sacro, lumbar, torácico y cervical, cada ocho horas, a partir de las 24 horas de la inoculación.

Cada médula espinal se retiró de la columna vertebral, después de la perfusión, y se dividió en tres partes: intumescencia cervical, intumescencia lumbosacra y el segmento intermedio entre ellas que corresponde a la médula torácica. Teniendo en cuenta la longitud promedio de cada segmento (cervical de $7 \mathrm{~mm}$; torácico de $12 \mathrm{~mm}$ y lumbosacro de $10 \mathrm{~mm})$ y el espesor de cada corte $(50 \mu \mathrm{m})$, el número aproximado total de cortes por segmento fue de 140 cervicales, 240 torácicos y 200 lumbosacros.

Para mantener la relación ipsilateral-contralateral, se hizo una pequeña incisión con bisturí a lo largo del lado contrario a la inoculación de toda la médula espinal después de retirarla de la columna vertebral.

Los cortes se recogieron en PBS dentro de recipientes de vidrio, semejantes a cajas de Petri, de $3 \mathrm{~cm}$ de diámetro y $1,5 \mathrm{~cm}$ de altura. Fueron necesarias dos o tres cajas para recoger todos los cortes de cada segmento. Todo el procedimiento inmunohistoquímico para revelar la presencia de antígenos de la rabia se desarrolló, con los cortes flotando dentro de estos recipientes, en agitación constante y a temperatura ambiente $\left(20-22{ }^{\circ} \mathrm{C}\right)$. Inicialmente, se dejaron en PBS hasta el día siguiente y se hicieron tres cambios de la solución durante ese tiempo de, aproximadamente, 20 horas. Los demás lavados se hicieron en PBS, con tres cambios de 10 minutos cada uno, después de cada tratamiento.

Los cortes se trataron con cloruro de amonio 0,05 $\mathrm{M}$, durante 30 minutos, para contrarrestar el efecto de los aldehídos. Después se trataron con peróxido de hidrógeno al $3 \%$ para bloquear la peroxidasa endógena y, posteriormente, se incubaron durante 30 minutos, en una solución compuesta por suero equino al $3 \%$, albúmina bovina al $3 \%$ y tritón al $10 \%$, para bloquear sitios inespecíficos y permeabilizar las membranas.

A continuación, se retiró la solución y, sin lavar, los cortes se incubaron en el anticuerpo primario; un antisuero antirrábico desarrollado anteriormente (17). La incubación se llevó a cabo en una dilución 1:2.500 durante dos horas. Posteriormente, los cortes se incubaron sucesivamente en el anticuerpo secundario 'biotinilado' (anti-conejo IgG Sigma, 1:600) durante 1 hora y en una solución preparada con el complejo ABC (Vector) por 1 hora adicional. El revelado fue hizo con un estuche de diaminobencidina y níquel (Vector).

Como controles de la reacción inmunohistoquímica, se utilizaron cortes de médula espinal de ratones de la misma edad y sexo, no inoculados con el virus y cortes de médula espinal de ratones infectados y sin tratamiento con anticuerpo primario. Para la localización neuroanatómica de las neuronas inmunorreactivas al virus de la rabia, se utilizaron como guía atlas especializados en médula espinal de ratón $(18,19)$.

\section{Resultados}

La primera evidencia de la presencia de antígenos de la rabia en la médula espinal se observó a las 24 horas después de la inoculación. Estos se manifestaron como pequeñas inclusiones dentro del asta ventral de la médula lumbar, con ubicación ipsilateral a la extremidad posterior inoculada, a nivel de los segmentos L5-L6 (figura 1A). Partículas como estas no se observaron en ninguno de los dos tipos de controles, como tampoco en segmentos más caudales de la médula espinal de los animales infectados.

A las 32 horas después de la inoculación se hicieron visibles las primeras neuronas que contenían antígeno suficiente para demarcar la morfología completa de las células (pericarion y dendritas). Estas se localizaron en el asta ventral de la médula 
lumbar ipsilateral, entre los segmentos L5-L6, dentro del grupo de núcleos neuronales de la lámina 9 (figuras $1 \mathrm{~B}$ y $\mathrm{C}$ ), en la misma ubicación en la que previamente, a las 24 horas después de la inoculación, se habían observado los primeros antígenos.

A las 48 horas después de la inoculación, el virus se había dispersado a otras neuronas dentro de la sustancia gris de los dos lados de la médula lumbar (L3-L6) (figura 1D).

A las 40 horas después de la inoculación se observaron las primeras neuronas inmunorreactivas al virus, en la médula torácica ipsilateral al miembro inoculado, localizadas en la región medial de la sustancia gris, en un área correspondiente a la lámina 8 (núcleo $8 \mathrm{Sp}$ ) (figura $2 \mathrm{~A}$ ), a nivel de los segmentos T11-T13.

A las 48 horas después de la inoculación se reveló la presencia de las primeras neuronas inmunorreactivas en la médula cervical correspondiente a los segmentos C4-C6. Estas se ubicaron también en la zona medial ipsilateral al sitio de inoculación, dentro de la lámina 8 (figuras $2 \mathrm{~B}$ y $\mathrm{C}$ ).

A las 56 horas después de la inoculación se observaron neuronas inmunorreactivas dispersas en la sustancia gris de los dos lados de la médula cervical.

Teniendo en cuenta que la longitud promedio de la médula espinal extraída de cada ratón infectado, y medida entre la intumescencia lumbar y la intumescencia cervical, fue de $32 \mathrm{~mm}(\mathrm{n}=20)$, el virus alcanzó una velocidad de desplazamiento de $2 \mathrm{~mm} /$ hora entre la médula lumbar y la cervical durante las 16 horas que tardó en hacer el recorrido. La velocidad pudo ser ligeramente mayor si se tiene en cuenta que la fijación produce retracción del tejido.

Aquí es importante destacar que, aun cuando el virus ya se había diseminado por toda la médula espinal, a las 56 horas de la inoculación, los animales no manifestaban ningún signo de la enfermedad. No había señales de decaimiento ni pelo erizado, ni se había afectado su locomoción, pese a que, probablemente, la mayoría de motoneuronas ya habían sido infectadas.

Apenas a partir de las 96 horas de la inoculación de este experimento, se observaron los primeros signos que consistían en parálisis parcial de las extremidades posteriores. En la fase terminal de la enfermedad (a partir de las 120 horas de la inoculación), los animales estaban completamente postrados, sin movimiento alguno. La inmunorreacción en todos los niveles de la médula espinal exhibió una densa concentración de antígenos

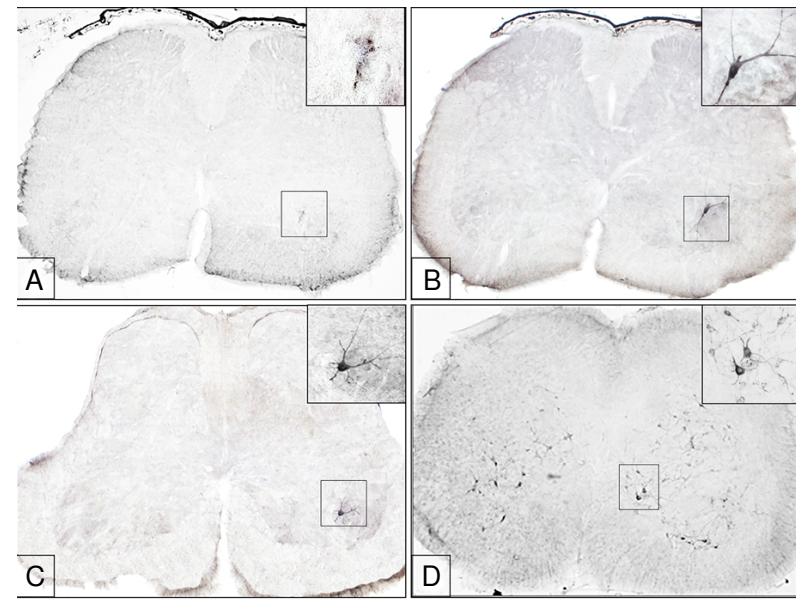

Figura 1. Inmunorreacción del virus de la rabia en cortes transversales de médula lumbar de ratón. A: Antígenos virales revelados en el asta ventral (L6) a las 24 horas de la inoculación. B y C: Motoneuronas del núcleo Hm9, a nivel de L6 (B) y L5 (C), a las 32 horas de la inoculación. El contenido de antígenos virales es tan alto que permite demarcar la morfología de las células. D: A las 48 horas de la inoculación, el virus se ha dispersado a neuronas de los dos lados de la sustancia gris (L3) (Imágenes panorámicas en 5X y ampliaciones en 40X). Nótese que los antígenos localizados en A están en la misma ubicación de la neurona inmunoreactiva observada en $\mathrm{B}$.

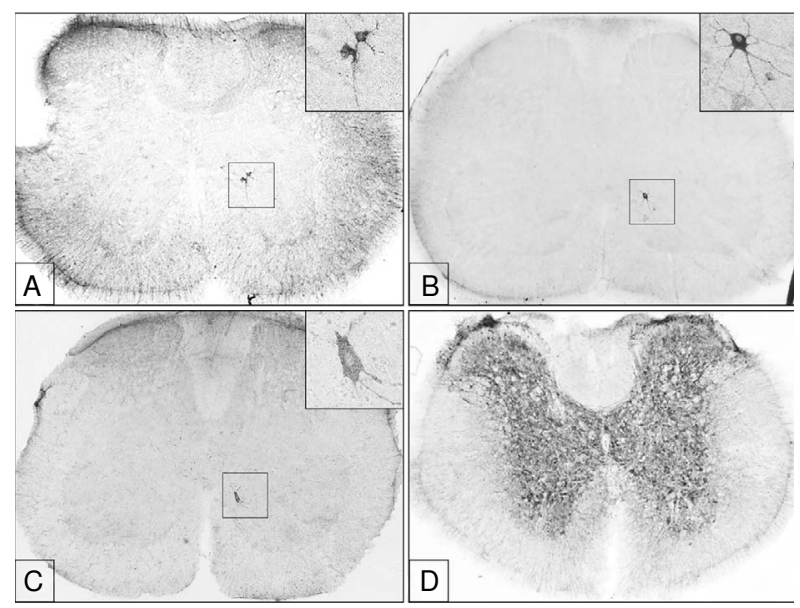

Figura 2. A. Neuronas inmunorreactivas al virus de la rabia localizadas en la lámina $8 \mathrm{Sp}$ de la médula torácica (T12) a las 40 horas de la inoculación. B y C. Neuronas inmunopositivas para rabia en la lámina $8 \mathrm{Sp}$ de la médula cervical C6 (B) y C4 (C) a las 48 horas de la inoculación. D. Inmunorreacción a la rabia en fase avanzada de la enfermedad (a las 120 horas de la inoculación) en la médula torácica (T13) (Imágenes panorámicas en $5 \mathrm{X}$ y ampliaciones en 40X).

virales en la sustancia gris (figura 2D). En las figuras 3 y 4 , se resumen esquemáticamente los procesos de dispersión y ascenso del virus dentro de la médula espinal. 


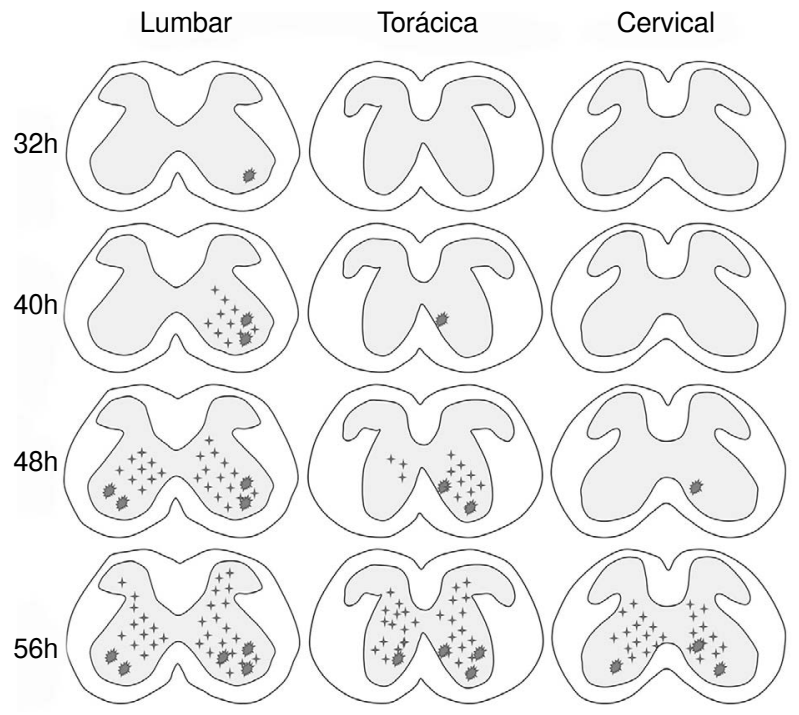

Figura 3. Representación gráfica de la diseminación del virus de la rabia en la médula espinal de ratón desde el nivel lumbar hasta el nivel cervical entre las 32 y las 56 horas de la inoculación. Mientras el virus asciende a los niveles siguientes, simultáneamente se dispersa en la sustancia gris de los dos lados.

\section{Discusión}

Después de la inoculación intramuscular del virus en las extremidades posteriores de los ratones, los antígenos virales se localizaron inicialmente en el asta ventral de la médula lumbar, en núcleos correspondientes a motoneuronas. El núcleo $\mathrm{Hm} 9$ contiene específicamente motoneuronas que inervan los músculos isquiotibiales (18-21).

La evidencia neuroanatómica de distribución de las neuronas inmunorreactivas aquí descrita, sugiere que, a partir de la médula lumbar, el virus asciende mediante transporte axonal retrógrado por la vía propioespinal. Esto se deduce por la localización de las neuronas en las que inicialmente se observaron antígenos en la médula torácica y la médula cervical. Los núcleos $8 \mathrm{Sp}$ de estos segmentos medulares contienen neuronas propioespinales con axones largos descendentes. Estas neuronas envían proyecciones monosinápticas directamente hasta los núcleos propioespinales inferiores y las neuronas motoras lumbares de la lámina $9(22,23)$.

En otras palabras, el virus inoculado en los músculos isquiotibiales es conducido a la médula espinal hasta las motoneuronas de la lámina 9 , y asciende por los axones descendentes de las neuronas propioespinales de la lámina 8 hasta los niveles torácico y cervical. Además, parte de las proyecciones de las neuronas propioespinales de la lámina 8 pertenecen a la comisura (22); estas podrían contribuir a la rápida diseminación del virus al lado contralateral. Estos resultados son evidencia de la mayor afinidad del virus de la rabia por la vía motora y del transporte axonal retrógrado como su principal mecanismo de diseminación. Las neuronas propioespinales descendentes se consideran premotoras (23) y contribuyen a la coordinación de los reflejos y la locomoción (22).

Aquí se revelan detalles, aparentemente no conocidos, sobre el transporte del virus de la rabia por la médula espinal. Son escasos los estudios sobre rabia que se enfocan en esta parte del sistema nervioso. La mayoría de ellos tratan sobre la histopatología post mortem (24-26), y otros se limitan a informar el tiempo transcurrido entre la inoculación periférica del virus y su aparición en la médula lumbar, pero sin precisar el sitio exacto

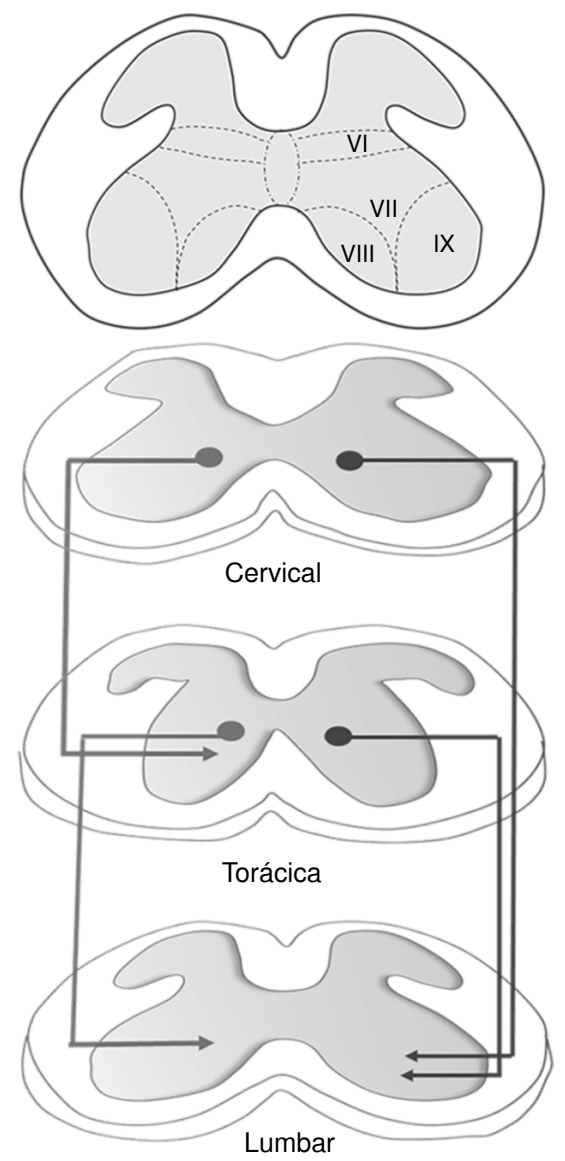

Figura 4. Descripción de las vías de ascenso del virus de la rabia, por transporte retrógrado desde la médula lumbar hasta la médula cervical. Las flechas de la derecha indican las proyecciones propioespinales, desde la médula cervical y torácica hacia los núcleos motores de la médula lumbar. Las flechas de la izquierda representan las conexiones descendentes entre núcleos propioespinales. 
y sin hacer seguimiento posterior a su ascenso por los diferentes niveles (12,27-29). Además, los intervalos de observación reportados son cada 24 horas o más, a partir de la inoculación, mientras que en el presente estudio se hizo un seguimiento cada 8 horas. Esto facilitó la detección de las primeras neuronas infectadas en cada uno de los niveles de la médula espinal.

Por otra parte, la velocidad de diseminación del virus estuvo dentro del rango reportado en estudios in vitro (1-2 $\mathrm{mm}$ por hora) para su transporte axonal retrógrado $(2,7,12,30)$. Igualmente, el tiempo de llegada del virus de la rabia desde su inoculación periférica intramuscular hasta la médula lumbar, está dentro del rango de 24 horas reportado en otros estudios en ratón $(12,29)$. No obstante, en sus estudios con rata, cobayo y primates, Ugolini ha establecido que se requieren, en promedio, 48 horas para que el virus inoculado por vía periférica sea detectado en las neuronas de primer orden en la médula espinal y, después, 12 horas para su paso a neuronas de segundo orden, independientemente de la distancia $(7,31)$. En los resultados aquí presentados para ratón, estos intervalos de tiempo son ostensiblemente menores.

En la revisión bibliográfica no se encontraron estudios similares que detallen el ascenso del virus por la vía motora, desde la médula lumbar a la médula cervical, con excepción del trabajo realizado recientemente con un virus de rabia modificado genéticamente (desprovisto de la proteína G), utilizado solo como trazador monosináptico, porque ha perdido la capacidad de reproducirse y de pasar de una neurona a otra por vía transináptica (23). Con este trazador, se demostraron las conexiones monosinápticas entre las neuronas propioespinales de la médula torácica y la médula cervical con las motoneuronas lumbares. Un aspecto particular de este virus recombinante utilizado como trazador, es que el recorrido entre la médula lumbar y la médula cervical, en los ratones utilizados, tardó aproximadamente una semana.

Por otra parte, de acuerdo con sus experimentos en ratas, cobayos y primates, Ugolini sostiene que el ingreso del virus desde la periferia hasta la médula espinal ocurre exclusivamente por fibras motoras. Esto lo ha demostrado inoculando músculos que contienen abundantes fibras sensoriales, motoras y autonómicas. En ningún caso encontró diseminación del virus por vía sensorial o autonómica, y sugiere que los reportes sobre la posible entrada del virus de la rabia por vía sensorial en ratones podrían explicarse por una mayor vulnerabilidad de esta especie ante el virus CVS, puesto que esta cepa viral fue originalmente adaptada en ratón $(7,31)$. Esta mayor vulnerabilidad también explicaría el transporte más rápido del virus desde la periferia hasta la médula espinal y desde las motoneuronas hasta las neuronas propioespinales descendentes, hallado en ratones en el presente estudio. Ahora bien, la diseminación del virus por la ruta intramuscular parece ser más eficiente, si se tiene en cuenta el estudio más reciente que reportó el ingreso del virus CVS por la vía sensorial en ratones, en un tiempo de 96 horas después de la inoculación para su transporte desde la periferia hasta la médula espinal lumbar (11).

Finalmente, es importante destacar el hecho de que la diseminación del virus por la médula espinal, no se manifiesta por disfunción motora sino hasta bien avanzada la enfermedad, cuando el virus ya ha invadido áreas motoras superiores del encéfalo. Previamente, se había demostrado el efecto de la infección, en fase avanzada de la enfermedad, sobre la expresión de proteínas reguladoras del metabolismo del calcio en la médula espinal (32). Que el virus de la rabia no genere alteraciones funcionales como resultado de su dispersión temprana por la médula espinal, es coherente con otros estudios que han demostrado la estrategia del agente patógeno para asegurar su diseminación por todo el tejido nervioso, sin afectar la función neuronal sino hasta bien avanzada la enfermedad $(2,30,33)$. Esto es particularmente importante en la médula espinal para permitir el avance de la infección hacia el encéfalo.

\section{Agradecimientos}

A los funcionarios del Grupo de Virología por el suministro y mantenimiento de las cepas virales, y a los del Bioterio del Instituto Nacional de Salud por el suministro y mantenimiento de los animales de experimentación.

\section{Financiación}

Este trabajo fue financiado con recursos del Departamento Administrativo de Ciencia, Tecnología e Innovación (COLCIENCIAS) y el Instituto Nacional de Salud (INS-Colombia), Proyecto Código 210465740573 , Contrato No. 639 de 2014.

\section{Conflicto de intereses}

Los autores consideran que no existe ningún conflicto de intereses que pueda afectar la publicación este trabajo. 


\section{Referencias}

1. Murphy FA. Rabies pathogenesis. Brief review. Arch Virol.1977;54:279-97. https://doi.org/10.1007/BF01314774

2. Jackson AC, Zhen F. Pathogenesis. En: Jackson AC, editor. Rabies. Tercera edición. San Diego: Academic Press; 2013. p. 299-349.

3. Kristensson K. Retrograde transport of macromolecules in axons. Annu Rev Pharmacol Toxicol. 1978;18:97-110. https://doi.org/10.1146/annurev.pa.18.040178.000525

4. Tsiang $\mathbf{H}$. Evidence for an intraaxonal transport of fixed and street rabies virus. J Neuropathol Exp Neurol. 1979;38: 286-99. https://doi.org/10.1097/00005072-197905000-00008

5. Watson HD, Tignor GH, Smith AL. Entry of rabies virus into peripheral nerves mice. J Gen Virol. 1981;56:371-82. https://doi.org/10.1099/0022-1317-56-2-371

6. Gillet JP, Derer P, Tsiang H. Axonal transport of rabies virus in the central nervous system of the rat. J Neuropathol Exp Neurol. 1986;45:619-34.

7. Ugolini G. Rabies virus as a transneural tracer of neural connections. Adv Virus Res. 2011;79:165-202. https://doi. org/10.1016/B978-0-12-387040-7.00010-X

8. World Health Organization. WHO Expert consultation on rabies. En: Technical Report Series No. 982. Geneva: WHO Press; 2013. p. 1-139.

9. Tsiang H, Lycke E, Ceccaldi PE, Ermine A, Hirardot X. The anterograde transport of rabies virus in rat sensory dorsal root ganglia neurons. J Gen Virol. 1989;70:2075-85. https://doi.org/10.1099/0022-1317-70-8-2075

10. Castellanos J, Hurtado $\mathbf{H}$, Arias $\mathbf{J}$, Velandia A. Rabies virus infection of cultured adult mouse dorsal root ganglion neurons. Mem Inst Oswaldo Cruz. 1996;91:621-5. https:// doi.org/10.1590/S0074-02761996000500014

11. Velandia-Romero ML, Castellanos JE, Martínez-Gutiérrez M. In vivo differential susceptibility of sensory neurons to rabies virus infection. J Neurovirol. 2013;13:367-75. https:// doi.org/10.1007/s13365-013-0179-5

12. Coulon P, Derbin C, Kucera P, Lafay F, Prehaud C, Flamand A. Invasion of the peripheral nervous systems of adult mice by the CVS strain of rabies virus and its avirulent derivative AvO1. J Virol. 1989;63:3550-4.

13. Zampieri N, Jessell TM, Murray AJ. Mapping sensory circuits by anterograde trans-synaptic transfer of recombinant rabies virus. Neuron. 2014;81:766-78. https://doi. org/10.1016/j.neuron.2013.12.033

14. Haberl MG, Viana da Silva S, Guest JM, Ginger M, Ghanem A, Mulle C, et al. An anterograde rabies virus vector for high-resolution large-scale reconstruction of 3D neuron morphology. Brain Struct Funct. 2015;220:1369-79. https://doi.org/10.1007/s00429-014-0730-z

15. Heise C, Kayalioglu G. Cytoarchitecture of the spinal cord. En: Watson C, Paxinos G, Kayalioglu G, editores. The spinal cord. San Diego: Academic Press; 2009. p. 64-93.

16. Habel K. Habel Test For Potency. En: Meslin FX, Kaplan $\mathrm{MKH}$, editores. Laboratory techniques in rabies. Cuarta edición. Geneva: WHO Press; 1996. p. 369-73.

17. Lamprea NP, Ortega LM, Santamaría G, Sarmiento L, Torres-Fernández $\mathrm{O}$. Elaboración y evaluación de un antisuero para la detección inmunohistoquímica del virus de la rabia en tejido cerebral fijado en aldehídos. Biomédica. 2010; 30:146-51. https://doi.org/10.7705/biomedica.v30i1.162

18. Watson C, Paxinos G, Kayalioglu G, Heise Claire. Atlas of the mouse spinal cord. En: Watson C, Paxinos G, Kayalioglu $G$, editores. The espinal cord. San Diego: Academic Press; 2009. p. 308-79.

19. Sengul G. Watson C. Spinal Cord: En: Watson C, Paxinos G, Puelles L. The mouse nervous system. San Diego: Academic Press; 2012. p. 424-58.

20. McHanwell S, Biscoe TJ. The localization of motoneurons supplying the hindlimb muscles of the mouse. Phil Trans R Soc Lond B. 1981;293:477-508. https://doi.org/10.1098/ rstb.1981.0082

21. McHanwell S, Watson C. Localization of motoneurons in the spinal cord. En: Watson C, Paxinos G, Kayalioglu G, editores. The spinal cord. San Diego: Academic Press; 2009. p. 92-114.

22. Conta AC, Stelzner DJ. The propiospinal system. En: Watson C, Paxinos G, Kayalioglu G, editores. The spinal cord. San Diego: Academic Press; 2009. p. 178-90.

23. Ni Y, Nawabi H, Liu X, Yang L, Miyamichi K, Tedeschi A, et al. Characterization of long descending premotor propiospinal neurons in the spinal cord. J Neurosci. 2014;34:940417. https://doi.org/10.1523/JNEUROSCI.1771-14.2014

24. Juntrakul S, Ruangvejvorachai $\mathbf{P}$, Shuangshoti $\mathbf{S}$, Wacharapluesadee S, Hemachudha T. Mechanisms of scape phenomenon of spinal cord and brainstem in human rabies. BMC Infect Dis. 2005;5:104. https://doi.org/10. 1186/1471-2334-5-104

25. Kojima D, Park CH, Satoh Y, Inoue S, Noguchi A, Oyamada T. Pathology of the spinal cord of C57BL/6J mice infected with rabies virus (CVS-11) strain. J Med Vet Sci. 2009;71:319-24. https://doi.org/10.1292/jvms.71.319

26. Bassuino DM, Konradt G, Cruz RA, Silva GS, Gomes DC, Pavarini SP, et al. Characterization of spinal cord lesions in cattle and horses with rabies: the importance of correct sampling. J Vet Diagn Invest. 2016;28:455-60. https://doi. org/10.1177/1040638716647992

27. Dean DJ, Evans WM, McClure RC. Pathogenesis of rabies. Bull World Health Organ. 1963;29:803-11.

28. Baer GM, Shanthaveerappa TR, Bourne GH. Studies on the pathogenesis of fixed rabies virus in rats. Bull World Health Organ. 1965;33:783-94.

29. Watson HD, Tignor GH, Smith AL. Entry of rabies virus into the peripheral nerves of mice. J Gen Virol. 1981;56:37182.https://doi.org/10.1099/0022-1317-56-2-371

30. Tsiang H. Pathophysiology of rabies virus infection of the nervous system. Adv Virus Res.1993;42:375-412.

31. Ugolini G. Use of rabies virus as transneuronal tracer of neuronal connections: Implications for the understanding of rabies pathogenesis. Dev Biol (Basel). 2008;131:493-506.

32. Monroy-Gómez J, Torres-Fernández $\mathbf{O}$. Distribución de calbindina y parvoalbúmina y efecto del virus de la rabia sobre su expresión en la médula espinal de ratones. Biomédica. 2013;33:564-73. https://doi.org/10.7705/biomedica. v33i4.1552

33. Lamprea $\mathbf{N}$, Torres-Fernández $\mathbf{O}$. Evaluación inmunohistoquímica de la expresión de calbindina en el cerebro de ratones en diferentes tiempos después de la inoculación con el virus de la rabia. Colomb Med. 2008;39(Supl.3):7-13. 